\title{
Effects of SCH-23390 Infused into the Amygdala or Adjacent Cortex and Basal Ganglia on Cocaine Seeking and Self-Administration in Rats
}

\author{
Andrea T Alleweireldt', Rebecca J Hobbs', Adam R Taylor' and Janet L Neisewander*,I \\ 'Department of Psychology, Arizona State University, Tempe, AZ, USA
}

\begin{abstract}
Amygdala DI receptors have been implicated in the motivating effects of cocaine-conditioned cues and cocaine itself, but the specific nucleus involved is unclear. Thus, we infused the DI antagonist, SCH-23390, into the rostral basolateral amygdala (rBLA), caudal basolateral amygdala (CBLA), or central amygdala (CEA), and tested its effects on self-administration of cocaine, as well as reinstatement of extinguished cocaine-seeking behavior by cocaine-conditioned cues or cocaine itself. Two anatomical controls, the posterior regions of basal ganglia (BG) and somatosensory/insular cortices (CTX), were also examined. Cocaine self-administration was increased and cue and cocaine reinstatement were decreased by $\mathrm{SCH}-23390$ infusion into every region when examined across the hour test session, with the exception that cBLA infusion did not alter cocaine reinstatement. In the first 20 min of the session, when $\mathrm{SCH}-23390$ was more localized in the target sites, self-administration was increased by infusion into the CEA, CBLA, BG, and CTX, with lesser increases in the rBLA. Cocaine reinstatement was attenuated during the first 20 min only by infusion into the CEA, rBLA, and CTX. Cue reinstatement was not reliably observed in the first 20 min, but there was a trend for attenuation by infusion into the CBLA, and surprisingly, significant attenuations in the BG and CTX. The findings suggest that DI receptors in subregions of the amygdala play differential roles in the reinforcing/motivational effects of cocaine, while the cue reinstatement effects are less clear. Further research is needed to examine the novel findings that neighboring regions of the BG and CTX may play a role in motivation for cocaine.

Neuropsychopharmacology (2006) 31, 363-374. doi: I0.1038/sj.npp. I300794; published online 15 June 2005
\end{abstract}

Keywords: caudate putamen; insular cortex; somatosensory cortex; dopamine DI receptors; reinstatement; marginal division

\section{INTRODUCTION}

Cocaine and cocaine-paired stimuli can elicit craving and relapse in cocaine abusers (Childress et al, 1988; Wallace, 1989). This phenomenon is modeled in animals using the extinction/reinstatement model, in which cocaine-seeking behavior (ie operant responding in the absence of cocaine reinforcement) is thought to reflect motivation for cocaine. Extinguished cocaine-seeking behavior can be reinstated by a cocaine priming injection or by response-contingent presentations of stimuli previously paired with cocaine infusions (ie cocaine cues), reflecting the incentive motivational effects of these stimuli (de Wit and Stewart, 1981).

Previous research has demonstrated that pretreatment with dopamine D1 receptor antagonist and agonist drugs

\footnotetext{
*Correspondence: Dr JL Neisewander, Department of Psychology, Arizona State University, Box 87I I04, Tempe, AZ 85287-I I04, USA, Tel: + I 480965 0209, Fax: + I 480965 8544,

E-mail: janet.neisewander@asu.edu

Received I4 January 2005; revised 22 April 2005; accepted 28 April 2005

Online publication: 10 May 2005 at http://www.acnp.org/citations/ Npp05 I 005050033/default.pdf
}

attenuates motivation elicited by either cocaine priming or cocaine cues (Self et al, 1996, 2000; Weissenborn et al, 1996; Khroyan et al, 2000; Ciccocioppo et al, 2001; Weiss et al, 2001; Alleweireldt et al, 2002, 2003). The effects of D1 agonists and antagonists on cocaine-primed reinstatement are reversed when the drugs are co-administered (Alleweireldt et al, 2003; Khroyan et al, 2003), suggesting D1 receptor mediation. Due to differential effects on response latency, we have proposed that different mechanisms are involved in the effects of D1 antagonists and agonists on cocaineseeking behavior, and that the effects of D1 antagonists result from the abolishment of the reinforcing effects of cues and cocaine primes (Alleweireldt et al, 2002).

The amygdala has been implicated in processing the salience of both conditioned and unconditioned stimuli, but subnuclei within the amygdala may differentially contribute to these effects. Specifically, excitotoxic lesion of the basolateral amygdala (BLA), but not the central amygdala (CEA), disrupts responding for a conditioned reinforcer (Burns et al, 1993; Robledo et al, 1996). Also, exposure to cocaine cues enhances immediate early gene expression, a marker for neuronal activity, in the BLA, but not the CEA (Neisewander et al, 2000; Ciccocioppo et al, 2001; Thomas 
and Everitt, 2001). On the other hand, expression of a different neuronal activity marker, $\gamma$ protein kinase $\mathrm{C}$, is increased in both the BLA and CEA following cue exposure (Thomas et al, 2003). Furthermore, Kruzich and See (2001) reported that both the BLA and CEA are involved in the expression of cue-elicited cocaine-seeking behavior. However, the CEA may be more critical than the BLA for the vigor of cue-elicited cocaine-seeking behavior. For instance, we have shown that cocaine-seeking behavior intensifies during the course of withdrawal from cocaine (TranNguyen et al, 1998; Neisewander et al, 2000), and this phenomenon has become known as the 'incubation effect' (Grimm et al, 2001). A recent report has shown that increased phosphorylation of extracellular signal-regulated kinases (ERK) in the CEA, but not the BLA, is critical for the incubation effect observed with cue reinstatement of cocaine-seeking behavior ( $\mathrm{Lu}$ et al, 2005). The vigor of responding for conditioned cues is also potentiated by amphetamine infusion into the nucleus accumbens, an effect which is attenuated by lesion of the CEA, but not the BLA (Burns et al, 1993; Robledo et al, 1996). Thus, the CEA and BLA appear to play distinct, but somewhat overlapping roles in conditioned cue effects, with the BLA more involved in responding for conditioned cues and the CEA more involved in potentiation of this effect.

In contrast to its role in conditioned effects, the BLA does not appear to process unconditioned reward since lesion or inactivation fail to alter cocaine self-administration (Whitelaw et al, 1996; Meil and See, 1997; Grimm and See, 2000; Yun and Fields, 2003). The CEA, on the other hand, shows increased neuronal activity following self-stimulation of the medial forebrain bundle (Hunt and McGregor, 1998), the classic definition of brain reward. Also, infusion of amphetamine into the CEA, but not the BLA, supports conditioned place preference (O'Dell et al, 1999). Finally, cocaine itself, as opposed to cocaine cues, activates immediate early gene expression in the CEA, but not in the BLA (Neisewander et al, 2000; Ciccocioppo et al, 2001).

D1 receptors in the amygdala appear to be involved in both conditioned and unconditioned stimulus effects. Infusion of SCH-23390 into the amygdala attenuates the reinforcing and/or motivational effects of cocaine cues (See et $a l, 2001)$ as well as the reinforcing and discriminative stimulus effects of cocaine itself (McGregor and Roberts, 1993; Caine et al, 1995; Callahan and Cunningham, 1995; Hurd et al, 1997). However, it is presently unclear which amygdaloid nuclei contribute to these effects. We hypothesized that D1 receptors in the BLA, and possibly the CEA, are involved in motivation for cocaine elicited by conditioned reinforcers, whereas D1 receptors in the CEA, but not the BLA, are involved in motivation for cocaine elicited by the primary reinforcer, cocaine itself. To test this hypothesis, we first examined the effects of SCH-23390 infused into the CEA, rostal (r) BLA, or caudal (c) BLA on both cue- and cocaine-reinstated cocaine-seeking behavior, as well as on cocaine self-administration. The caudal basolateral amygdala (cBLA) is distinct from the rostral basolateral amygdala (rBLA) in both its anatomical connections (Groenewegen et al, 1990; Shinonaga et al, 1994) and contributions to cocaine-seeking behavior (Kantak et al, 2002). Also, since the drug is likely carried up the cannula track upon infusion, we explored anatomical specificity by examining effects of a single dose of $\mathrm{SCH}-23390$ infused into regions dorsal to the amygdala, the posterior caudate-putamen and globus pallidus of the basal ganglia (BG), and dorsolateral to the amygdala, the secondary somatosensory and insular cortices (CTX).

\section{MATERIALS AND METHODS}

\section{Animals and Surgery}

Male Sprague-Dawley rats, weighing 225-275g at the beginning of the experiment, were housed individually in a climate-controlled facility with a 12-h light/dark cycle. The housing conditions and care of the animals were in accordance with the Guide for the Care and Use of Laboratory Animals (National Research Council, 1996).

Rats were acclimated to handling for at least 5 days prior to surgery and until they achieved a weight of at least $275 \mathrm{~g}$. Rats received atropine sulfate $(10 \mathrm{mg} / \mathrm{kg}$, i.p.) to decrease bronchial secretions, and $5 \mathrm{~min}$ later, they were anesthetized with sodium pentobarbital (50 mg/kg, i.p.). Silastic catheters were then implanted into the jugular vein as described by Neisewander et al (2000). The catheter ran subcutaneously from the neck and exited through an incision on top of the head. After suturing the neck incision, the rat was placed into a stereotaxic instrument. The connective tissue overlying the skull was removed and four stainless steel screws were implanted into the skull. Small holes were then drilled into the skull, through which stainless steel guide cannulae (23-gauge) were lowered. Rats received bilateral cannulae implants into either the CEA, rBLA, cBLA, BG, or CTX according to the following stereotaxic coordinates relative to Bregma and derived from the atlas of Paxinos and Watson (1997):

\begin{tabular}{lccccc}
\hline & CEA & rBLA & CBLA & BG & CTX \\
\hline AP & -2.5 & -2.5 & -3.5 & -3.0 & -3.0 \\
ML & \pm 4.1 & \pm 5.0 & \pm 5.0 & \pm 4.8 & \pm 6.5 \\
DV & -6.5 & -6.7 & -7.0 & -5.0 & -5.0 \\
\hline
\end{tabular}

Dental acrylic was used to permanently affix the metal end of the catheter and the guide cannulae to the screws, which anchored the entire headpiece to the skull. Stainless steel stylets (30-gauge) were placed into the guide cannulae to prevent clogging. To maintain catheter patency, catheters were flushed daily throughout the self-administration phase of the experiment with $0.1 \mathrm{ml}$ of a solution of bacteriostatic saline, heparin sodium $(10 \mathrm{U} / \mathrm{ml})$, streptokinase $(0.67 \mathrm{mg} /$ $\mathrm{ml})$, and ticarcillin disodium $(66.67 \mathrm{mg} / \mathrm{ml})$. Catheter tips were sealed with a plastic cap when not in use. Catheter patency was verified periodically by injecting animals intravenously with $0.03-0.05 \mathrm{ml}$ of methohexal sodium $(16.67 \mathrm{mg} / \mathrm{ml})$, which produces a rapid loss of muscle tone only when administered intravenously.

\section{Drugs and Intracranial Infusions}

(+ )-SCH-23390 (Sigma, St Louis, MO) was first dissolved in methanol and then diluted with heated, distilled water to 
produce a stock concentration. Lower doses were made via serial dilution. All dosage solutions, as well as vehicle, contained methanol at $5 \%$ concentration. The $\mathrm{pH}$ of the vehicle solution was matched to the $\mathrm{pH}$ of the highest drug concentration $(\mathrm{pH} \approx 4.9)$.

Rats received bilateral infusions of an assigned dose of drug or vehicle into either the CEA, rBLA, cBLA, BG, or CTX immediately prior to each test phase. A 30-gauge injector connected to a $10-\mu$ l syringe via PE 10 tubing was lowered to extend either exactly $1 \mathrm{~mm}$ (early experiments) or $2 \mathrm{~mm}$ (later experiments) below the guide cannulae tips. After $1 \mathrm{~min}$, rats received $0.2 \mu \mathrm{l}$ of $\mathrm{SCH}-23390$ or vehicle infused over $1 \mathrm{~min}$. Infusion of the drug was confirmed by movement of an air bubble the correct distance in the injection tubing. Injectors remained in place for $1 \mathrm{~min}$ to allow diffusion away from the injector and then stylets were replaced. Intracranial infusion produces temporary behavioral effects in some rats, such as reduced muscle tone, circling, and/or stereotypy. Thus, a maximum of $4 \mathrm{~min}$ postinfusion was allowed for rats to recover from these effects before being placed into the chambers for testing. Most rats required only $2 \mathrm{~min}$ to return to normal activity and many were placed into the chambers as soon as stylets were replaced.

\section{Cocaine Self-Administration Training Phase}

After at least 5 days of recovery from surgery, rats were trained to lever press for cocaine infusions $(0.75 \mathrm{mg} / \mathrm{kg}$ per $0.1 \mathrm{ml}$, i.v.) during daily, 2-h sessions. The operant conditioning chambers were equipped with two levers mounted on the front wall (one lever was 'active' and the other 'inactive'), a cue light above the active lever, a tone generator, and a house light mounted on the center of the back wall. Each chamber was housed in a larger, soundattenuating chamber. Completion of the schedule of reinforcement on the active lever simultaneously activated the house light, illuminated the cue light above the lever, and activated a tone. After $1 \mathrm{~s}$, the 6-s cocaine infusion was delivered. The cue light and tone were then inactivated and the house light remained on for a 20-s timeout period, during which active lever presses had no consequences. Based on their individual self-administration performance, rats progressed from a fixed ratio (FR) 1 schedule to a variable ratio (VR) 2, VR 3, and finally to a VR 5 schedule of reinforcement. This schedule of partial reinforcement, as opposed to the continuous FR 1 schedule, was chosen because it engenders more robust responding when reinforcement is withheld (Mowrer and Jones, 1945). Rats were food-restricted to approximately $17 \mathrm{~g} /$ day beginning 2 days prior to training as this has been shown to facilitate acquisition of cocaine self-administration (Carroll et al, 1981), and they remained food-restricted until they achieved 14 infusions/session for two consecutive days on a VR 3 schedule of reinforcement. Thereafter, rats were given access to food ad libitum in the home cage throughout the remainder of the experiment. Rats received a minimum of 14 days self-administration training and were maintained on the VR 5 schedule with free food access for at least 5 days. Responses on the inactive lever were recorded but had no consequence.

\section{Cocaine Self-Administration Test Phase}

Before testing for self-administration, rats had to demonstrate stable infusion rates across days on the VR 5 schedule, defined as less than $15 \%$ variability of infusions/ session across 2 days of self-administration and no upward or downward trends across 3-5 days. Rats were tested twice for self-administration, once following infusion of vehicle and once following infusion of their assigned dose of SCH23390, counterbalanced for order. Cocaine was available on a VR 5 schedule during the 1-h test session. At least 2 days intervened test days for rats to demonstrate that they had returned to their stable baseline self-administration rate, or a minimum of 3 days to demonstrate stability at a new level of intake, as was sometimes the case. Rats were infused bilaterally with SCH-23390 $(0.5,1.0$, or $2.0 \mu \mathrm{g} /$ side $)$ into the CEA, rBLA, or cBLA (final $n=4-8$ per group). To examine region specificity of the $\mathrm{SCH}-23390$ effects observed in the amygdala, additional rats received bilateral infusions of $2.0 \mu \mathrm{g} /$ side into the BG or CTX (final $n=7-8$ per group).

\section{Extinction Phase}

Following self-administration, rats underwent daily 1-h extinction sessions. They were placed into the chambers and lever presses were recorded, but produced no consequences. Extinction continued a minimum of 10 days to obtain a low baseline from which responding could be reinstated by cues or cocaine priming. The extinction session immediately preceding a reinstatement test served as the baseline for that test.

\section{Cocaine and Cue Reinstatement Test Phases}

For cocaine reinstatement, an i.p. cocaine priming injection $(10 \mathrm{mg} / \mathrm{kg})$ was administered immediately before the rat was placed into the operant conditioning chamber. Lever presses were recorded for a 1-h test session, but had no consequences (ie no cues were presented). To control for possible reinstatement due to injection stress, rats were given an i.p. saline injection on the extinction day immediately preceding the cocaine reinstatement test (ie baseline). For cue reinstatement, the same stimulus complex as that paired with cocaine during training, with the exception that no fluid was infused with pump onset, was delivered response-contingently on an FR 1 schedule across the $1-h$ test session. If a rat did not receive a cue in the first 5 min of the session, a noncontingent cue presentation was delivered. Rats were tested twice for cocaine reinstatement and twice for cue reinstatement. The order of test type was counterbalanced such that half the rats were tested first for cocaine reinstatement (two tests) and then for cue reinstatement (two tests) and the other half were tested in the reverse order. For each test type, rats were pretreated with vehicle on one test day and an assigned dose of drug on the other test day, counterbalanced for order, and separated by at least 4 days of extinction to re-establish the baseline. A minimum of 2 extinction days separated a cocaine and cue test.

In separate experiments, rats received bilateral amygdala infusions of SCH-23390 into either the CEA $(0.125-2.0 \mu \mathrm{g} /$ side), rBLA $(0.5-2.0 \mu \mathrm{g} / \mathrm{side})$, or cBLA $(0.25-2.0 \mu \mathrm{g} / \mathrm{side}$; 
final $n=6-11$ per group). To further assess anatomical specificity, additional rats were injected with $2.0 \mu \mathrm{g} /$ side of SCH-23390 into the BG (final $n=9-10$ ). Additional rats with cannulae directed at the CTX were tested with bilateral infusions of the minimally effective dose of SCH-23390, which was $1.0 \mu \mathrm{g} / \mathrm{side}$ for cue reinstatement and $2.0 \mu \mathrm{g} / \mathrm{side}$ for cocaine reinstatement $(n=8-9)$. The between-subjects assignment to dosage group was counterbalanced for previous cocaine intake during self-administration training since this variable is positively correlated with reinstatement of cocaine-seeking behavior (Deroche et al, 1999; Baker et al, 2001). For each rat, the dose assignment was held constant for cocaine and cue reinstatement testing, but the dose assignment for self-administration varied and was balanced across reinstatement dosage groups. Only about half the rats who were tested for reinstatement were also tested for self-administration due to fewer doses tested and lower power needed to detect effects. Since a within-subjects design was utilized, rats who failed to reinstate to a cocaine prime or to cues were excluded from the respective analyses. 'Reinstatement' was defined as an increase of at least 10 active lever presses above baseline on either the vehicle- or SCH-23390-pretreatment test day.

\section{Histology}

After testing, animals were deeply anesthetized with sodium pentobarbital ( $100 \mathrm{mg} / \mathrm{kg}$, i.p.), decapitated, and their brains were removed and sectioned in the coronal plane at a thickness of $40-60 \mu \mathrm{m}$. Appropriate sections were thawmounted onto gelatin-coated slides and stained with thyonin or cresyl violet for assessment of cannulae placement and neurotoxicity by an observer blind to the rats' treatment and performance.

\section{Statistical Analyses}

Rats' performance on each baseline day (infusion rate or response rate) was subtracted from their performance on the respective test day, and these difference scores were analyzed separately for the active and inactive lever for the first $20 \mathrm{~min}$ of the sessions as well as for the full hour. Data from each test type and each brain region were analyzed using separate ANOVAs. For amygdala subregions, difference scores for the vehicle and drug tests were analyzed using a mixed factor $2 \times 3-5$ ANOVA with drug treatment (ie vehicle $v s \mathrm{SCH}-23390$ ) as the within subjects factor and dosage group as the between-subjects factor. For the BG and CTX, the difference scores were analyzed using repeatedmeasures ANOVA with drug treatment as the factor. Due to graded dose-response functions and strong main effects observed in the amygdala subregions, planned pairedsample $t$-tests were also used to make the most relevant comparisons between behavior on the vehicle $v s$ drug pretreatment test days for each dosage group. Finally, to ensure that vehicle-treated rats exposed to cues or a cocaine prime demonstrated reinstatement of cocaine-seeking behavior above baseline levels, planned paired-sample $t$-tests were used to compare responding on the vehicle pretreatment test day to responding on the baseline day for each dosage group. Latency to the first active lever press was also examined using ANOVAs as described above.

\section{RESULTS}

All descriptive statistics are presented as mean \pm SEM and all significant effects are reported. Approximately $27 \%$ of the rats implanted with cannula were excluded from analyses due to a misplaced cannula or extensive damage to the target nucleus. Figure 1 shows acceptable regions for infusion sites while a representative photomicrograph is presented in Figure 2.

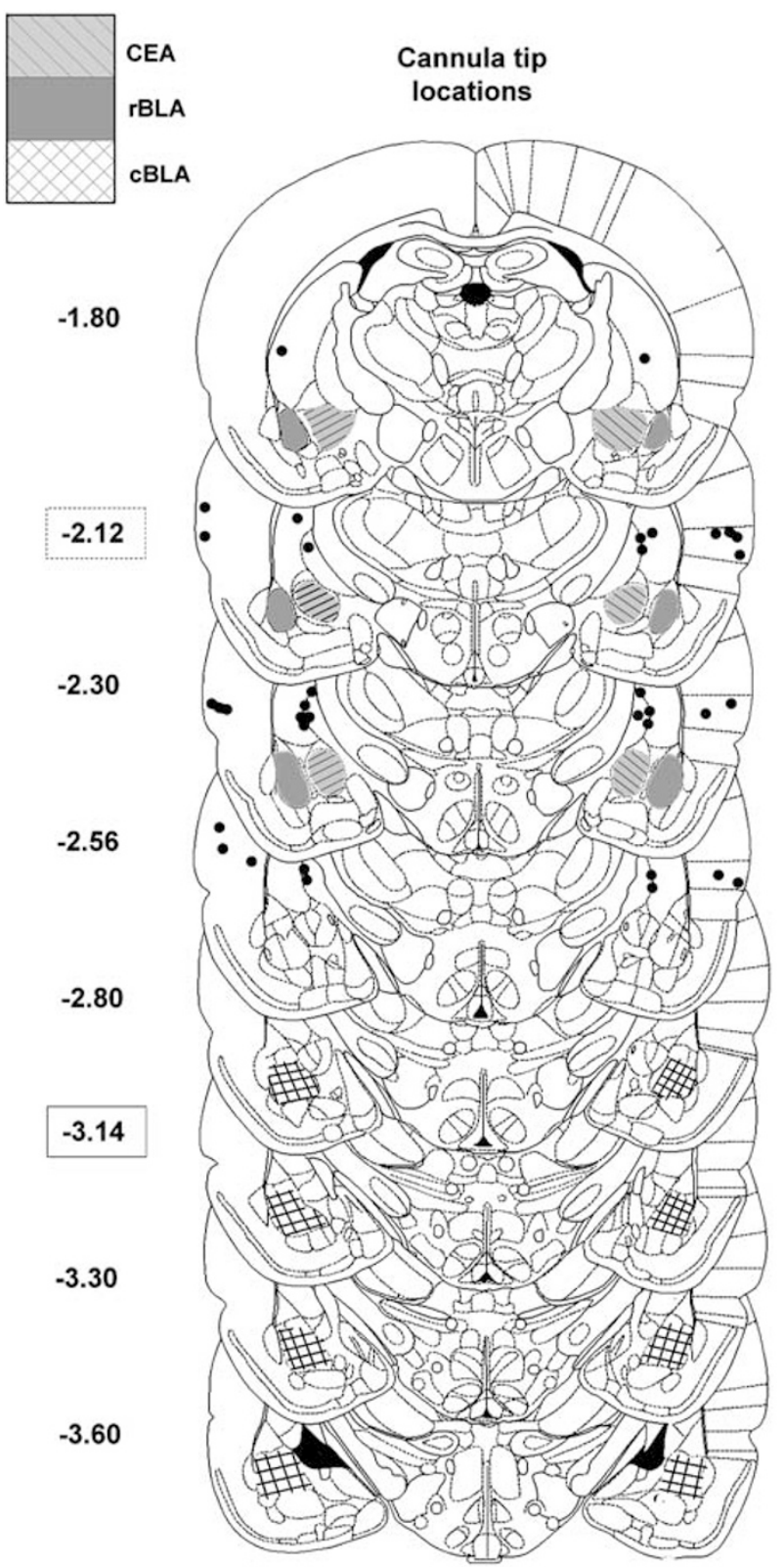

Figure I Rats were included in the data analyses only if their cannulae tips were located in the target regions indicated for each of the three amygdala nuclei. The anterior/posterior plate containing the most infusion points is boxed with a dashed line for the CEA and $r B L A$ and a solid line for the CBLA. The individual infusion sites for the BG and CTX anatomical control regions are indicated by the symbols. The numbers indicate distance from Bregma in $\mathrm{mm}$. Schematic representations were taken from Paxinos and Watson (1997), with the permission of Elsevier. 

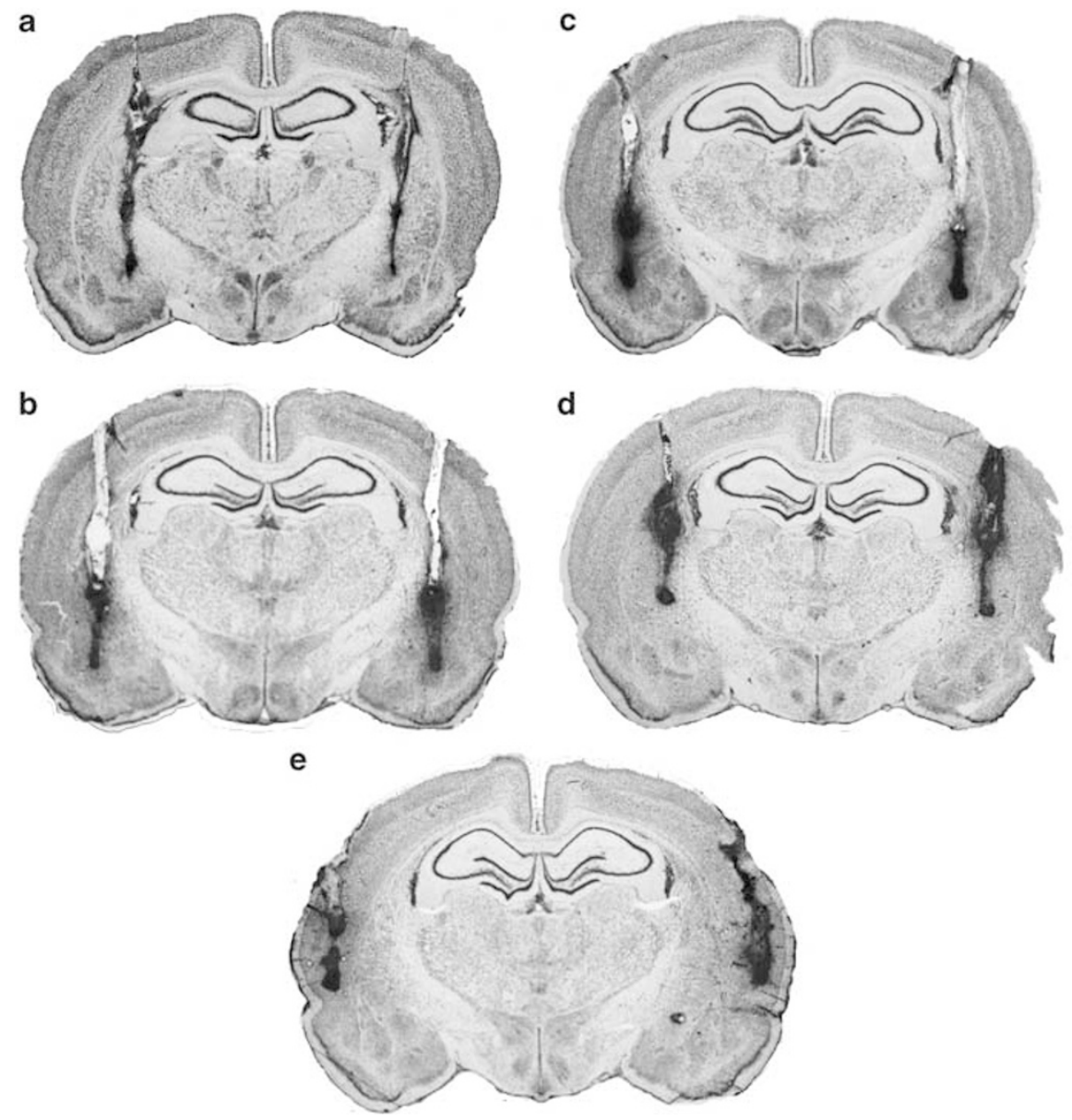

Figure 2 Representative photomicrograph of coronal sections of rat brains with cannula either aimed at the CEA (a), rBLA (b), cBLA (c), BG (d), or CTX (e). Sections were cut at $40 \mu \mathrm{m}$ and stained with cresyl violet.

Table I Self-Administered Cocaine Infusions (mean \pm SEM)

\begin{tabular}{lcc}
\hline Brain region & Average daily infusions & Total infusions \\
\hline CEA $(N=51)$ & $25.38 \pm 0.97$ & $572.36 \pm 25.10$ \\
CBLA $(N=34)$ & $23.98 \pm 1.18$ & $510.38 \pm 26.04$ \\
rBLA $(N=33)$ & $24.83 \pm 1.15$ & $627.21 \pm 41.28$ \\
BG $(N=10)$ & $23.75 \pm 2.51$ & $558.90 \pm 63.74$ \\
CTX $(N=8)$ & $23.15 \pm 2.56$ & $582.13 \pm 64.22$ \\
\hline
\end{tabular}

Each cocaine infusion contained $0.75 \mathrm{mg} / \mathrm{kg}$.

\section{Self-Administration}

Cocaine intake during self-administration training did not differ between experiments (see Table 1). Across all 136 rats, total intake averaged $569.76 \pm 16.50$ infusions for the entire experiment and daily intake averaged $24.65 \pm 0.59$ infusions/2-h session.

\section{Extinction}

Active lever responding on the first day of extinction did not differ between experiments. The average across experi- ments was $77.96 \pm 4.13$ responses/h. The average baseline level of responding for each of the two cue reinstatement tests and for the two cocaine reinstatement tests did not differ across experiments. Cue reinstatement baselines averaged $12.62 \pm 0.67$ and cocaine reinstatement baselines averaged $12.42 \pm 0.61$.

\section{Inactive Lever Responses and Response Latency}

No significant effects were detected for inactive lever presses in any of the experiments. For cue reinstatement tests, baseline rates averaged $10.04 \pm 0.86$ and test day rates averaged $9.93 \pm 0.90$. For cocaine reinstatement, baseline rates averaged $9.78 \pm 0.83$ and test day rates averaged $25.45 \pm 6.54$. Although this increase in rates on the test day relative to the baseline day was significant when rates were averaged across experiments, it was not significant within any single experiment. There were also no significant effects for latency to the first inactive or active lever press (see Table 2).

\section{Effects of SCH-23390 on Cocaine Self-Administration}

As shown in Figure 3, intra-amygdala SCH-23390 infusion increased cocaine self-administration, as did infusion of 
Table 2 Latency to the First Response (min; mean \pm SEM) during Cue and Cocaine Reinstatement Tests Following Either Vehicle or $\mathrm{SCH}-23390$ Pretreatment

\begin{tabular}{|c|c|c|c|c|c|c|c|c|}
\hline & \multicolumn{4}{|c|}{$1.0 \mu \mathrm{g} / \mathrm{side}$} & \multicolumn{4}{|c|}{$2.0 \mu \mathrm{g} / \mathrm{side}$} \\
\hline & \multicolumn{2}{|c|}{ Cues } & \multicolumn{2}{|c|}{ Cocaine } & \multicolumn{2}{|c|}{ Cues } & \multicolumn{2}{|c|}{ Cocaine } \\
\hline CEA & $2.2 \pm 1.4$ & $0.8 \pm 0.1$ & $2.8 \pm 1.8$ & $1.2 \pm 0.3$ & $7.5 \pm 6.1$ & $0.6 \pm 0.3$ & $6.8 \pm 5.9$ & $4.1 \pm 3.4$ \\
\hline cBLA & $1.6 \pm 0.4$ & $3.5 \pm 2.2$ & $2.5 \pm 0.9$ & $5.4 \pm 2.5$ & $6.3 \pm 5.3$ & $0.8 \pm 0.4$ & $3.1 \pm 1.7$ & $1.6 \pm 1.0$ \\
\hline$B G$ & & & & & $0.4 \pm 0.3$ & $15.5 \pm 14.6$ & $1.0 \pm 0.3$ & $7.3 \pm 4.8$ \\
\hline CTX & $0.9 \pm 0.4$ & $1.2 \pm 0.5$ & & & & & $1.8 \pm 0.8$ & $4.7 \pm 3.7$ \\
\hline
\end{tabular}

$2.0 \mu \mathrm{g} /$ side SCH-23390 into the BG or CTX. The only region to display a significant drug treatment by dosage group interaction was the $\operatorname{cBLA}(\mathrm{F}(2,15)=3.73, p<0.05)$, and this effect was only evident across the hour session, not in the first $20 \mathrm{~min}$. Follow-up simple main effects of dosage group were only evident for SCH-23390 pretreatment tests $(\mathrm{F}(2,15)=8.19, p<.005)$, not vehicle tests. Post hoc analyses revealed a significant difference between rats pretreated with 0.5 and $2.0 \mu \mathrm{g} / \mathrm{side}$ (Tukey tests, $p<0.005$ ). All regions except the cBLA showed main effects of drug treatment for both the full-hour session (CEA, $F(1,18)=36.61$; rBLA, $\mathrm{F}(1,14)=6.00 ; \quad \mathrm{BG}, \quad \mathrm{F}(1,6)=12.59, \quad \mathrm{CTX}, \quad \mathrm{F}(1,7)=8.72$, $p<0.05$ ) and the first $20 \mathrm{~min}$ of the session (CEA, $\mathrm{F}(1,14)=21.96 ; \quad \mathrm{rBLA}, \quad \mathrm{F}(1,14)=8.89 ; \quad \mathrm{BG}, \quad \mathrm{F}(1,6)=8.59$; CTX, $\mathrm{F}(1,7)=6.84, p<.005)$.

Planned comparisons between the SCH-23390 and vehicle tests for each amygdala region and dosage group revealed no significant effects in the rBLA. For the CEA, comparisons across the full-hour session revealed increases at all doses, while comparisons in the first $20 \mathrm{~min}$ only revealed increases for the two lower doses. For the cBLA, the two highest doses showed significant increases across the hour, but only the highest dose was significantly different in the first $20 \mathrm{~min}$ (paired $t$-tests, $p<0.05$; see Figure 3).

\section{Effects of SCH-23390 on Cocaine Reinstatement}

Of all the rats tested for cocaine reinstatement, $11 \%$ failed to reinstate to cocaine on both their vehicle and SCH-23390 test days and were excluded from analyses. As shown in Figure 4, SCH-23390 decreased cocaine reinstatement across the hour when infused into all regions except the cBLA. For the CEA, analyses revealed a drug pretreatment by dosage group interaction for both the hour session $(\mathrm{F}(1,4)=3.29, p<0.05)$ and the first $20 \mathrm{~min}(\mathrm{~F}(1,4)=3.16$, $p<0.05)$. Simple main effect tests showed significant effects of dosage group following SCH-23390 pretreatment, but not vehicle pretreatment, for both the hour $(\mathrm{F}(4,46)=2.88, p<0.05)$ and first $20 \mathrm{~min}(\mathrm{~F}(4,45)=3.18$, $p<0.05$ ), with significant decreases at the 1.0 and $2.0 \mu \mathrm{g} /$ side doses of SCH-23390 relative to the $0.125 \mu \mathrm{g} /$ side dose (Tukey tests, $p<0.05$ ). Also, when compared to responding on the vehicle test day, a significant decrease was found following infusion of the 0.25 and $2.0 \mu \mathrm{g} /$ side doses of
SCH-23390 for the full hour and at the $2.0 \mu \mathrm{g} /$ side dose for the first $20 \mathrm{~min}$ (paired $t$-tests, $p<0.05$ ). The rBLA and CTX also showed main effects of drug treatment for the hour session ( $\mathrm{rBLA}, \mathrm{F}(1,30)=8.94 ; \mathrm{CTX}, \mathrm{F}(1,7)=20.75, p<0.01)$ as well as the first $20 \mathrm{~min}$ ( $\mathrm{rBLA}, \mathrm{F}(1,29)=4.50$; CTX, $\mathrm{F}(1,7)=10.92, \quad p<0.01)$. Planned comparisons revealed significant differences between vehicle and drug infusions at the $2.0 \mu \mathrm{g} /$ side dose for the rBLA (paired $t$-tests, $p<0.05$ ). While infusion in the $\mathrm{BG}$ decreased cocaine reinstatement across the hour session $(\mathrm{F}(1,9)=8.28, p<0.05)$, it only produced a trend for a decrease in the first $20 \mathrm{~min}$ $(\mathrm{F}(1,9)=4.56, p=0.062)$. In the $\mathrm{cBLA}$, there was a trend for a main effect of drug treatment across the full-hour session $(F(1,30)=3.25, \quad p=0.08)$, with no significant attenuation at any given dose of SCH-23390 and no effects in the first $20 \mathrm{~min}$.

Finally, comparisons of baseline responding under extinction to responding following intracranial vehicle infusion and a cocaine prime revealed a significant increase for all regions and dosage groups for the full hour as well as the first $20 \mathrm{~min}$ (paired sample $t$-tests, $p<0.05$ ). Thus, all rats reinstated to a cocaine prime on their vehicle test day.

\section{Effects of SCH-23390 on Cue Reinstatement}

Of all the rats tested for cue reinstatement, $20 \%$ failed to reinstate to cues on both their vehicle and SCH-23390 test days, and were excluded from analyses. As shown in Figure 5, intra-amygdala SCH-23390 infusion dose-dependently decreased cue reinstatement, as did $2.0 \mu \mathrm{g} / \mathrm{side}$ $\mathrm{SCH}-23390$ infused into the BG and $1.0 \mu \mathrm{g} /$ side infused into the CTX. Across the entire hour session, main effects of drug treatment were evident for all regions except for the CEA $\quad(r B L A, F(1,20)=14.55 ; \quad c B L A, F(1,27)=13.57 ; \quad B G$, $\mathrm{F}(1,8)=11.15 ; \quad \mathrm{CTX}, \mathrm{F}(1,8)=6.81, p<0.05)$, although a trend was evident in the CEA $(\mathrm{F}(1,42)=3.89, p=0.055)$. Planned comparisons revealed significant differences between vehicle and drug infusions at both the 1.0 and $2.0 \mu \mathrm{g} /$ side doses for the rBLA and cBLA $(p<0.05)$, but only at the $1.0 \mu \mathrm{g} / \mathrm{side}$ dose for the CEA. When restricting analyses to the first $20 \mathrm{~min}$ of the session, main effects of drug treatment were evident in the cBLA $(\mathrm{F}(1,27)=$ $11.68, p<0.005)$, BG $(\mathrm{F}(1,8)=7.31, p<0.05)$, and CTX $(\mathrm{F}(1.8)=7.14, p<0.05)$, with a strong trend in the rBLA 
Cocaine self-administration

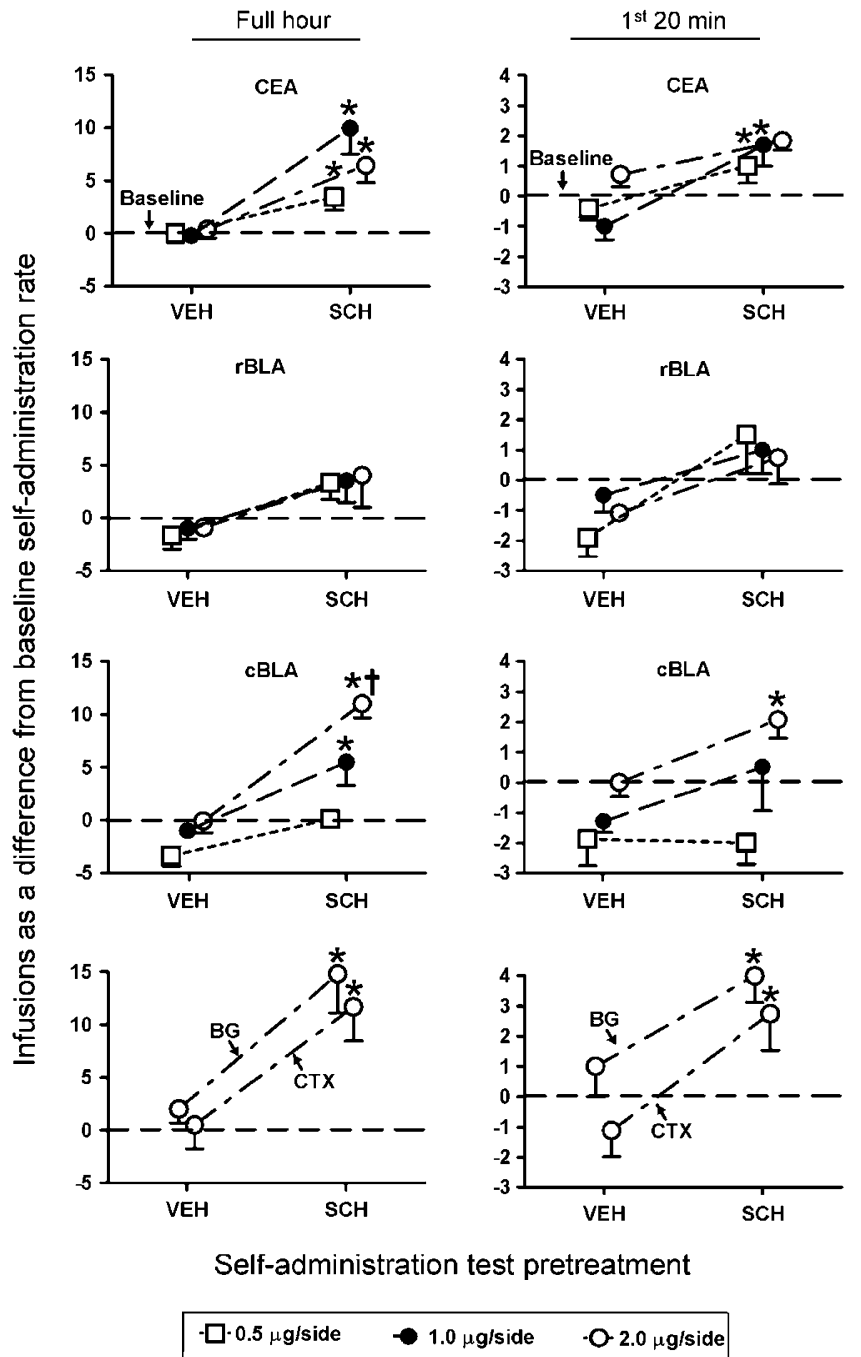

Figure 3 Effects of $\mathrm{SCH}-23390$ infused into the CEA, rBLA, CBLA, BG, and CTX on cocaine self-administration, expressed as a difference from baseline infusion rate (CEA, $n=6-8 ; c B L A, n=4-7 ; r B L A, n=5-6 ; B G$, $n=7 ;$ CTX, $n=8$ ). Data are presented for the full-hour session as well as for the first $20 \mathrm{~min}$ of the session. Each rat was tested twice, pretreated once with vehicle and once with their assigned dose of SCH-23390, counterbalanced for order. At least 2 days of stable self-administration intervened these tests. Average baseline follows for each region. Baseline for hour data: CEA, 15.02 \pm 0.52 ; rBLA, 15.74 \pm I.04; cBLA, 16.94 \pm 0.61 ; BG, 13.72 \pm 1.05 ; CTX, 15.41 \pm 1.75 . Baselines for first 20 min data: CEA, $6.39 \pm 0.31 ; r B L A, 6.56 \pm 0.52 ; c B L A, 7.49 \pm 0.35 ; B G, 4.19 \pm 0.84 ; C T X$, $6.5 \pm 0.76$. * represents a difference from vehicle pretreatment, pairedsample t-tests, $p<0.05$. † represents a difference from the lowest $\mathrm{SCH}-23390$ pretreatment dose $(0.5 \mu \mathrm{g} / \mathrm{side})$, Tukey post hocs, $p<0.005$.

$(\mathrm{F}(1,20)=3.96, p=0.06)$. Using planned $t$-tests for the individual doses within the amygdala subregions, no significant effects were found, and the only trends $(p<0.10)$ were in the cBLA $(0.25,1.0$, and $2.0 \mu \mathrm{g} / \mathrm{side})$. Thus, at any single dose, the only significant effects on cue reinstatement in the first 20 min occurred in the BG and CTX.

Finally, reinstatement of responding by cue presentation was assessed by comparisons of baseline responding under extinction to responding in the presence of cocaine-paired

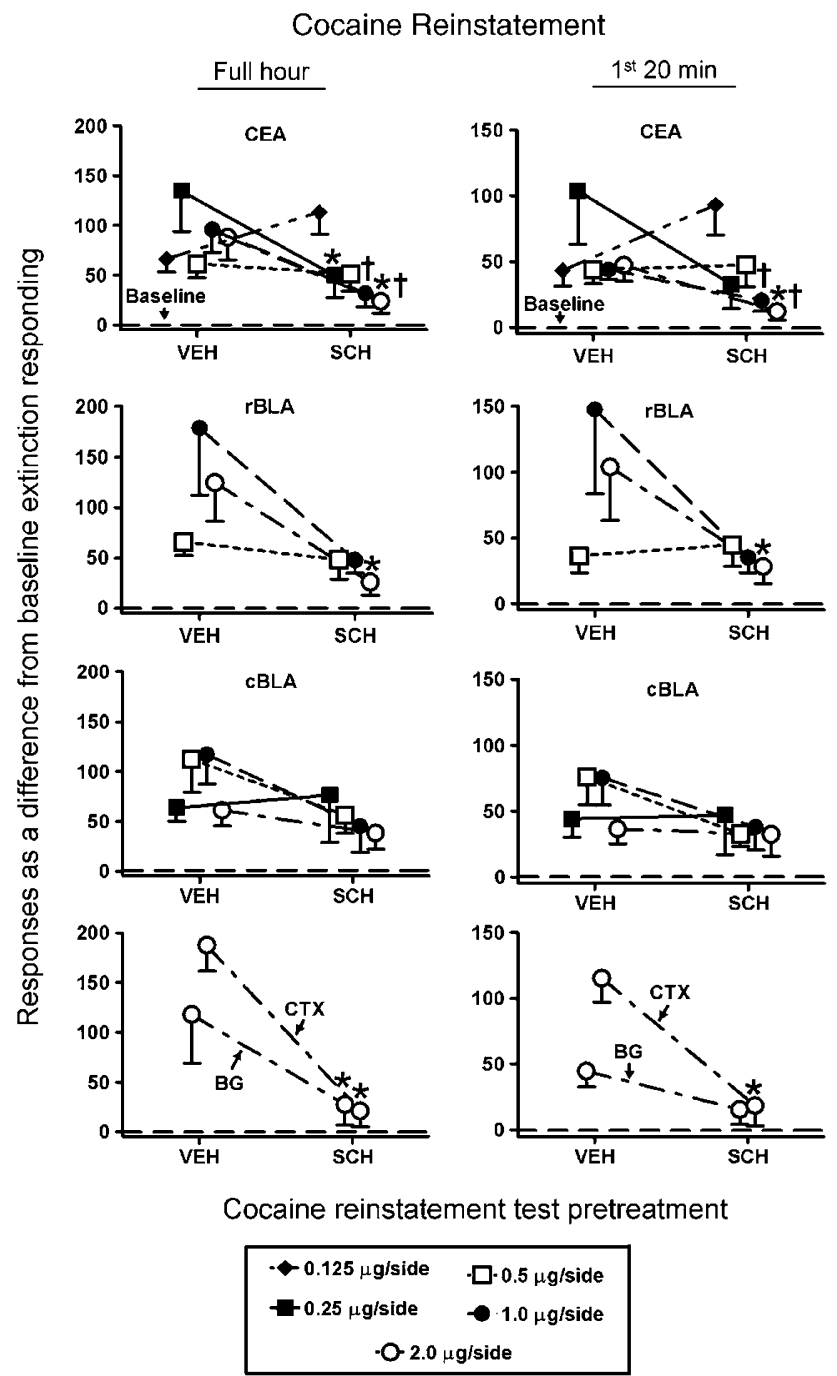

Figure 4 Effects of $\mathrm{SCH}-23390$ infused into the CEA, rBLA, CBLA, and $B G$ and $C T X$ on cocaine reinstatement, expressed as a difference from baseline extinction rate of responding (CEA, $n=7-14$; $c B L A, n=8-9$; $r B L A, n=10-11 ; B G, n=10 ; C T X, n=8)$. Data are presented for the full hour of the session as well as for the first 20 min of the session. Each rat was tested twice for cocaine reinstatement, pretreated once with vehicle and once with their assigned dose of $\mathrm{SCH}-23390$, counterbalanced for order. At least 4 days of extinction intervened tests. Baseline extinction response rates did not differ between vehicle and $\mathrm{SCH}-23390$ pretreatment tests or across experiments. The average baseline for the full-hour test data is $12.39 \pm 0.61$ and for the first $20 \mathrm{~min}$ data is $6.79 \pm 0.37$. * represents a difference from vehicle pretreatment, paired-sample $t$-tests, $p<0.05$. $\dagger$ represents a difference from the lowest $\mathrm{SCH}-23390$ pretreatment dose $(0.125 \mu \mathrm{g} / \mathrm{side})$, Tukey post hocs, $p<0.05$.

cues following vehicle infusions. These tests revealed a significant increase for all brain regions and dosage groups for the full hour (paired $t$-tests, $p<0.05$ ). However, cue reinstatement following vehicle pretreatment was not always evident in the first $20 \mathrm{~min}$, as was the case for rats in the $2.0 \mu \mathrm{g} / \mathrm{side}$ dosage groups for the CEA, rBLA, and cBLA, as well as for rats in the $0.5 \mu \mathrm{g} /$ side dosage group for the CEA. These findings demonstrate unreliable sensitivity to detect a cue reinstatement effect in the first $20 \mathrm{~min}$ of the session. 


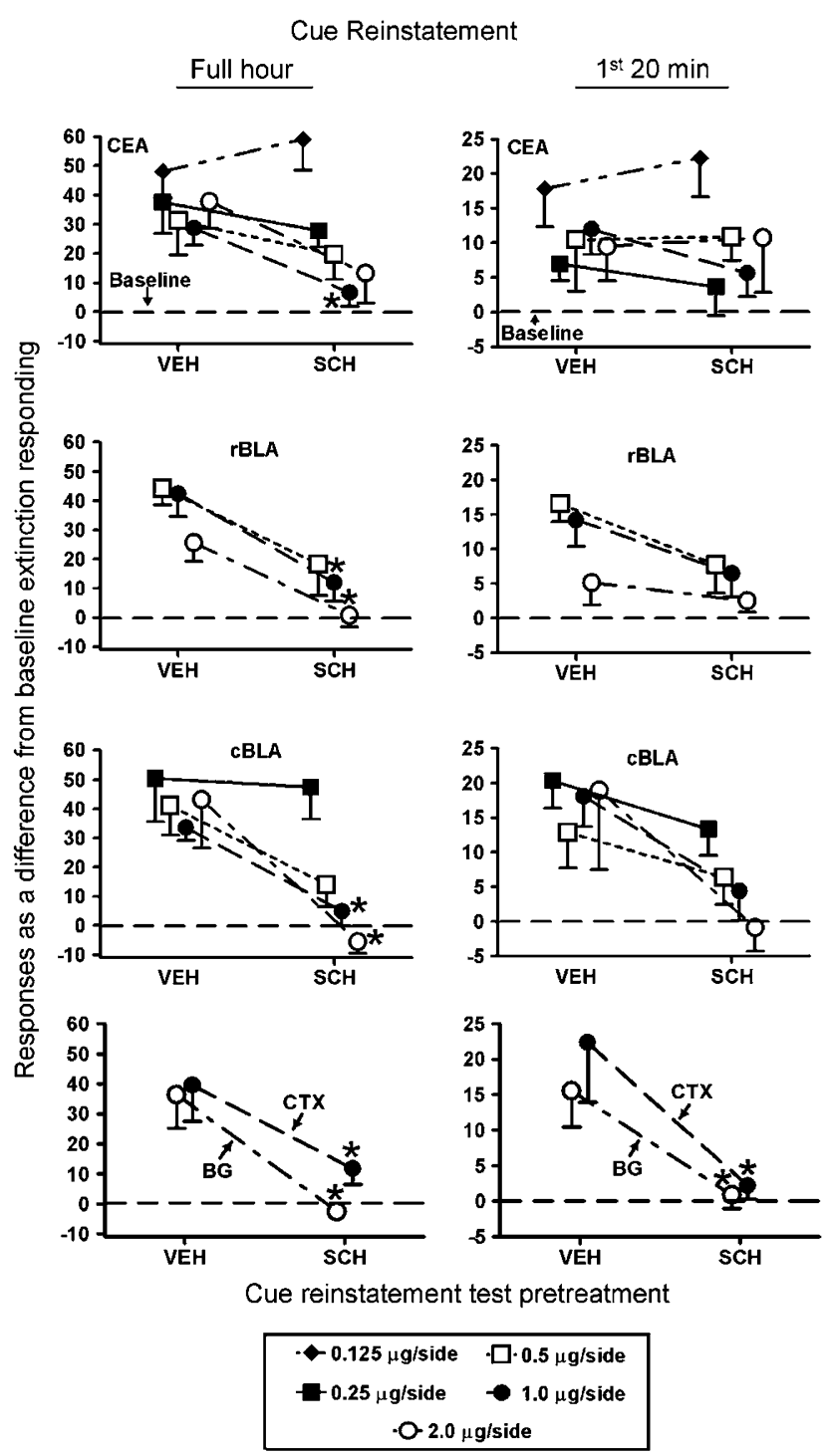

Figure 5 Effects of $\mathrm{SCH}-23390$ infused into the CEA, rBLA, cBLA, and $B G$ and $C T X$ on cue reinstatement, expressed as a difference from baseline extinction rate of responding (CEA, $n=8-11$; cBLA, $n=7-8$; rBLA, $n=$ $6-10 ; B G, n=9 ; C T X, n=9$ ). Data are presented for the full hour of the session as well as for the first 20 min of the session. Each rat was tested twice for cue reinstatement, pretreated once with vehicle and once with their assigned dose of SCH-23390, counterbalanced for order. At least 4 days of extinction intervened tests. Baseline extinction response rates did not differ between vehicle and $\mathrm{SCH}-23390$ pretreatment tests or across experiments. The average baseline for the full-hour test data is $12.77 \pm 0.65$ and for the first $20 \mathrm{~min}$ data is $7.38 \pm 0.36$. * represents a difference from vehicle pretreatment, paired-sample $t$-tests, $p<0.05$.

\section{DISCUSSION}

The present findings were unexpected in that intracranial infusion of SCH-23390 produced behavioral effects in every brain region examined. However, the pattern of effects between amygdala nuclei differed somewhat, particularly within the cBLA and when comparing effects occurring in the first $20 \mathrm{~min}$ (see Table 3). These region-specific differences suggest that $\mathrm{SCH}-23390$ produced effects via action at the target site, and not via spread to a neighboring region. Furthermore, previous literature suggests that our
Table 3 Comparison of SCH-23390 Effects Across Regions for the Full Hour (Left Symbol) and the First 20 min (Right Symbol)

\begin{tabular}{llllll}
\hline & CEA & rBLA & CBLA & BG & CTX \\
\hline Self-administration & $\uparrow \uparrow$ & $\uparrow \uparrow$ & $\uparrow \uparrow$ & $\uparrow \uparrow$ & $\uparrow \uparrow$ \\
Cocaine reinstatement & $\downarrow \downarrow$ & $\downarrow \downarrow$ & $\varnothing \varnothing$ & $\downarrow \downarrow$ & $\downarrow \downarrow$ \\
Cue reinstatement & $\downarrow ?$ & $\downarrow \downarrow$ & $\downarrow \downarrow$ & $\downarrow \downarrow$ & $\downarrow \downarrow$ \\
\hline
\end{tabular}

infusion parameters should have been sensitive enough to produce region-specific effects between the amygdala and dorsal anatomical control infusion sites. Intracranial SCH23390 infusion has produced region-specific behavioral effects with doses comparable to or higher than those used in the present study and with only $1-2 \mathrm{~mm}$ distance between target and dorsal anatomical control sites (Epping-Jordan et al, 1998; Ranaldi and Wise, 2001; Anderson et al, 2003; Quinlan et al, 2004), even following infusion into the BLA (Nader and LeDoux, 1999). Nevertheless, Caine et al (1995) demonstrated that infusion of $\left[{ }^{3} \mathrm{H}\right] \mathrm{SCH}-23390$ into the CEA produces a diffusion field of approximately $2 \mathrm{~mm}^{3}$ after an hour. Since some of our infusion coordinates were separated by less than $2 \mathrm{~mm}$, it is still possible that $\mathrm{SCH}$ 23390 spread beyond the amygdala during the hour, and therefore we will place emphasis on data from the first 20 min of testing when the drug should have been more localized to the infusion site.

As predicted, $\mathrm{SCH}-23390$ infusion into the CEA produced more robust and reliable effects on cocaine self-administration and cocaine reinstatement than on cue reinstatement. Specifically, self-administration was increased and cocaine reinstatement decreased to a similar extent in the first $20 \mathrm{~min}$ of the session as across the full hour, suggesting a region-specific effect. On the other hand, cue reinstatement was only attenuated across the hour by the $1.0 \mu \mathrm{g} / \mathrm{side}$ dose of SCH-23390, with no effects at the higher, $2.0 \mu \mathrm{g} / \mathrm{side}$ dose. While the $20 \mathrm{~min}$ data are unreliable for cue reinstatement, it is noteworthy that no doses showed even trends for significance in the first $20 \mathrm{~min}$ after CEA infusions, as seen by the flat-sloped lines in Figure 5. However, this may be due to low levels of responding during vehicle testing. These findings suggest that D1 receptors in the CEA are involved in processing the primary rewarding effects of cocaine; however, it remains unclear whether these receptors are also involved in processing the conditioned reinforcing effects of cocaine cues. The effects of intra-CEA SCH-23390 on cocaine self-administration and cocaine reinstatement were likely due to an attenuation of cocaine reward since such an effect would be expected to manifest as a compensatory increase in self-administration, but a reduction in the reinstating efficacy of a cocaine prime given the present experimental parameters (eg Caine et al, 1995; Burmeister et al, 2003). Furthermore, these opposite effects on response rates demonstrate that SCH-23390 effects on lever pressing were not due to a general disruption of motor behavior.

While low levels of responding in the first $20 \mathrm{~min}$ of cue reinstatement tests render this data difficult to interpret, the orderly dose-effect patterns in the rBLA and cBLA across both the hour and first 20 min suggest that $\mathrm{SCH}-23390$ was 
acting in these regions to attenuate responding, with more robust effects observed in the cBLA. Consistent with this suggestion, previous findings using dopamine receptor antagonists (See et al, 2001; Di Ciano and Everitt, 2004b), as well as lesion and inactivation approaches, implicate the BLA in cue-elicited motivation for cocaine (Meil and See, 1997; Grimm and See, 2000; Kruzich and See, 2001; Fuchs and See, 2002; Kantak et al, 2002; McLaughlin and See, 2003).

Although infusion into the rostral and caudal BLA produced similar effects on cue reinstatement, interesting differences were detected between these regions for cocaine self-administration. For the rBLA, main effects of drug treatment were evident at both the hour and first $20 \mathrm{~min}$, but no significant effects were evident at any given dose. Thus, effects were weak, not dose-dependent, and only observable with a large number of rats. These effects may have been produced by spread of SCH-23390 to a neighboring region, such as the CEA, where effects were evident at lower doses and more reliable in the first $20 \mathrm{~min}$, consistent with previous research (Caine et al, 1995). This interpretation is supported by several reports that BLA lesion and inactivation fail to alter cocaine self-administration (Meil and See, 1997; Grimm and See, 2000; Kantak et al, 2002; Yun and Fields, 2003). On the other hand, infusion into the cBLA significantly increased self-administration at both the 1.0 and $2.0 \mu \mathrm{g} / \mathrm{side}$ doses of SCH-23390 across the hour, with the highest dose still effective in the first $20 \mathrm{~min}$. These findings suggest that D1 receptors in the cBLA are involved in self-administration, although perhaps to a lesser extent than the CEA, in which SCH-23390 infusion produced more potent effects. The cBLA findings are consistent with previous research demonstrating significant increases in cocaine self-administration in the first $10 \mathrm{~min}$ after SCH-23390 infusion into the BLA (Hurd et al, 1997).

An opposite pattern of effects was observed for cocaine reinstatement, in which SCH-23390 infusion into the cBLA produced no effect, while infusion of the highest dose into the rBLA and CEA attenuated it to the same extent in the first $20 \mathrm{~min}$ as in the hour. Previous research has yielded inconsistent findings regarding the role of the CEA and BLA in cocaine reinstatement. For instance, a cocaine priming injection that reinstates cocaine-seeking behavior elicits immediate early gene expression in the CEA, but not in the BLA (Neisewander et al, 2000), and cocaine reinstatement is not attenuated by inactivation of the CEA or BLA (Grimm and See, 2000; McFarland and Kalivas, 2001). On the other hand, excitotoxic lesion of the BLA attenuates cocaine reinstatement (Yun and Fields, 2003), and SCH-23390 infusion into the CEA attenuates the discriminative stimulus effects of cocaine (Callahan and Cunningham, 1995), findings consistent with the present study.

Infusion into both the rBLA and cBLA produced seemingly discrepant effects on cocaine self-administration and cocaine reinstatement, with infusion into each region producing strong effects on one behavior and weak or no effects on the other. However, similar behavioral dissociations have been observed following excitotoxic lesion of the BLA (Yun and Fields, 2003) or SCH-23390 infusion into the dorsal prefrontal cortex (Sun and Rebec, 2005), suggesting that different neural mechanisms mediate the reinforcing effects of self-administered cocaine $v s$ the reinstating effects of a cocaine prime. Furthermore, McGregor and Roberts (1993) reported that SCH-23390 infused into the amygdala increased the number of self-administered cocaine infusions, but not the breakpoint on a progressive ratio schedule (ie the maximum number of responses a rat will emit to obtain a cocaine infusion), a measure thought to reflect motivation for cocaine. Conversely, infusion into the nucleus accumbens did not alter infusion rate, but decreased the breakpoint. The authors suggested that the amygdala may mediate the 'stimulus cue' properties of cocaine, while the nucleus accumbens links these properties to response reinforcement. In this light, it is interesting that SCH-23390 infusion into the rBLA altered cocaine reinstatement to a greater extent than self-administration, while infusion into the cBLA produced the opposite pattern. Kantak et al (2002) also observed differences on cocaineseeking behavior following lidocaine inactivation of the rostral vs caudal BLA. Furthermore, the rBLA projects almost exclusively to the core, and not the shell, of the nucleus accumbens as well as to the dorsal agranular insular region of the prefrontal cortex, and not the prelimbic region, while the cBLA shows the opposite projection pattern (Groenewegen et al, 1990; Kita and Kitai, 1990; McDonald, 1991; Shinonaga et al, 1994). Thus, the regional differences within the BLA may be due to differential projections to other limbic brain regions implicated in cocaine self-administration and reinstatement, such as the nucleus accumbens and prefrontal cortex (eg Goeders and Smith, 1993; McFarland and Kalivas, 2001; Park et al, 2002; McFarland et al, 2003; Anderson et al, 2003; Capriles et al, 2003).

Surprising and novel findings of the present study were the robust effects of SCH-23390 infused into the BG and CTX. In the first $20 \mathrm{~min}$ of the session, infusion into either region significantly increased self-administration, while only infusion into the CTX significantly attenuated cocaine reinstatement. However, the strong trend observed in the $\mathrm{BG}$ suggests that this region may also play a role in cocaine reinstatement. Infusion of SCH-23390 into either the BG or CTX also robustly attenuated cue reinstatement in the first 20 min, suggesting that these regions may play a role in processing the incentive motivational effects of cocaine cues. Assuming that the BG and/or CTX are involved in cue reinstatement, it is possible that effects of SCH-23390 infusions into the BLA involve spread of drug up the cannula track to these regions. Indeed, BLA manipulations do not always attenuate cue-elicited cocaine seeking (Fuchs et al, 2002; Di Ciano and Everitt, 2004a) and several recent studies support a role for the BG and CTX. First, a distinct brain region in the posterior portion of the caudate putamen at the border with the globus pallidus, named the marginal division, is purported to have limbic characteristics implicated in memory and motivation (eg Shu, 2003; Shu et al, 2003a,b). Also, the insular cortex is activated in cocaine-addicted individuals during craving elicited by cocaine cues (Wang et al, 1999; Garavan et al, 2000; Bonson et al, 2002). Finally, it has been proposed that part of cocaine's abuse and addictive properties stem from its enhancement of somatosensory processing (ie Drouin and Waterhouse, 2004), particularly in relation to cueelicited craving for cocaine (Di Chiara, 1999). While the BG and CTX data are interesting, they are preliminary and 
require more extensive investigation of regional and pharmacological specificity.

Finally, it is unclear why such high concentrations of SCH-23390 are required to produce effects intracranially. In at least one study on expression of amphetamine-conditioned place preference, a previously acquired preference for the amphetamine-paired side was blocked by approximately $55 \mu \mathrm{g}$ SCH-23390 administered systemically or $0.02 \mu \mathrm{g}$ administered into the nucleus accumbens, more than a 2000-fold difference in drug amounts (Hiroi and White, 1991). However, in the present study and many other intracranial infusion studies, SCH-23390 amounts used intracranially are similar to those used systemically, with less than a 10-fold difference between them. Previous research has sought to address this concern by examining the percentage of D1 receptors occupied following either systemic or intra-accumbens SCH-23390 administration (Neisewander et al, 1995, 1998). These studies showed that similar percentages of receptors in the nucleus accumbens were occupied following approximately $9 \mu \mathrm{g}$ SCH-23390 administered systemically (Neisewander et al, 1998) or $6 \mu \mathrm{g}$ infused directly into the nucleus accumbens $(3 \mu \mathrm{g} / \mathrm{side}$; Neisewander et al, 1995). While it is not clear why direct intracranial administration does not more potently occupy D1 receptors than systemic administration, this finding is consistent with the common practice of utilizing similar amounts of SCH-23390 systemically and intracranially.

Alternatively, it is possible that such high concentrations of SCH-23390 are required because effects are not produced at D1 receptors, but at other receptors for which SCH-23390 has less affinity. For instance, SCH-23390 is a full-efficacy agonist at $5-\mathrm{HT}_{2 \mathrm{C}}$ receptors (Millan et al, 2001), which have been implicated in cocaine abuse-related behaviors (Callahan and Cunningham, 1995; Grottick et al, 2000; Fletcher et al, 2002, 2004; Burmeister et al, 2004; Filip et al, 2004). At the concentrations used intracranially, SCH-23390 also functions as an antagonist for $\mathrm{G}$ protein-coupled, inwardly rectifying potassium channels (GIRK; Kuzhikandathil and Oxford, 2002). GIRK channels are linked to various receptor systems which activate these channels when stimulated, including the dopamine D2 receptor. Thus, at the doses used in this and most other intracranial SCH-23390 studies, SCH-23390 may simultaneously antagonize the function of several other receptor systems via blockade of GIRK channels. Lower doses of SCH-23390 may be required to bind selectively to D1 receptors. In this light, it is interesting that while high doses of SCH-23390 attenuated cocaine reinstatement, the lowest dose of $\mathrm{SCH}-23390$ infused into the CEA, $0.125 \mathrm{~g} /$ side, exhibited a trend for an increase in cocaine reinstatement across both the hour $(p=0.063)$ and first $20 \mathrm{~min}(p=0.082$, see Figure 4$)$. Further research is needed to elucidate the pharmacological action of $\mathrm{SCH}$ 23390 responsible for the effects observed in the present study, perhaps by investigating intra-amygdala effects of the non-benzazepine D1 antagonist, SCH-39166, which has a different binding profile than SCH-23390 (Alburges et al, 1992; Duffy et al, 2000), as well as the non-lipophilic agonists SKF-38393 and SKF-81297.

To summarize, the effects of SCH-23390 were more widespread than predicted with similar effects occurring not only in three different amygdala locations, but in regions dorsal to the amygdala as well. These effects may have been due to pervasive drug spread throughout the brain, particularly considering the lipophilic nature of the drug and the high concentrations infused. Alternatively, previous literature and careful examination of data from the first $20 \mathrm{~min}$ of the test session suggest that the infusion parameters used in the present study should and do produce region-specific effects. For instance, while cocaine self-administration was more robustly altered by $\mathrm{SCH}$ 23390 infusion into the cBLA than the rBLA, the opposite was true for cocaine reinstatement, with no reliable effects occurring in the cBLA. These behavior- and region-specific differences are not parsimoniously explained by a pervasive, whole-brain effect of SCH-23390, but are more characteristic of a drug effect within the target region. Thus, the unexpected, robust effects observed in the BG and CTX suggest these regions are likely involved in the reinforcing and incentive motivational effects of cocaine and cocaine cues. Further research is needed to verify whether SCH-23390 effects are D1 receptor-mediated and to examine the role of the posterior caudate-putamen/globus pallidus and insular/somatosensory cortices in motivation for cocaine.

\section{ACKNOWLEDGEMENTS}

We thank Erin Lungren, Jessica Johnson, David Moritz, Laura Muhammad, and Thomas Shepherd for their expert technical assistance and Dr Cheryl Conrad, Dr Jeffrey Joyce, Dr Miles Orchinik, and Arturo Zavala for their helpful comments on an earlier version on this manuscript. This research was supported by NIDA grants DA11064 and DA06095, as well as by a grant from the Howard Hughes Medical Institute through the Biology Research Experience for Undergraduates program.

\section{REFERENCES}

Alburges ME, Hunt ME, McQuade RD, Wamsley JK (1992). D1-receptor antagonists: comparison of [3H]SCH39166 to [3H]SCH23390. J Chem Neuroanat 5: 357-366.

Alleweireldt AT, Kirschner KF, Blake CB, Neisewander JL (2003). D1-receptor drugs and cocaine-seeking behavior: investigation of receptor mediation and behavioral disruption in rats. Psychopharmacology (Berl) 168: 109-117.

Alleweireldt AT, Weber SM, Kirschner KF, Bullock BL, Neisewander JL (2002). Blockade or stimulation of D1 dopamine receptors attenuates cue reinstatement of extinguished cocaine-seeking behavior in rats. Psychopharmacology (Berl) 159: 284-293.

Anderson SM, Bari AA, Pierce RC (2003). Administration of the D1-like dopamine receptor antagonist $\mathrm{SCH}-23390$ into the medial nucleus accumbens shell attenuates cocaine priminginduced reinstatement of drug-seeking behavior in rats. Psychopharmacology (Berl) 168: 132-138.

Baker DA, Tran-Nguyen TL, Fuchs RA, Neisewander JL (2001). Influence of individual differences and chronic fluoxetine treatment on cocaine-seeking behavior in rats. Psychopharmacology (Berl) 155: 18-26.

Bonson KR, Grant SJ, Contoreggi CS, Links JM, Metcalf J, Weyl HL et al (2002). Neural systems and cue-induced cocaine craving. Neuropsychopharmacology 26: 376-386.

Burmeister JJ, Lungren EM, Kirschner KF, Neisewander JL (2004). Differential roles of 5-HT receptor subtypes in cue and cocaine reinstatement of cocaine-seeking behavior in rats. Neuropsychopharmacology 29: 660-668. 
Burmeister JJ, Lungren EM, Neisewander JL (2003). Effects of fluoxetine and d-fenfluramine on cocaine-seeking behavior in rats. Psychopharmacology (Berl) 168: 146-154.

Burns LH, Robbins TW, Everitt BJ (1993). Differential effects of excitotoxic lesions of the basolateral amygdala, ventral subiculum and medial prefrontal cortex on responding with conditioned reinforcement and locomotor activity potentiated by intra-accumbens infusions of D-amphetamine. Behav Brain Res 55: 167-183.

Caine SB, Heinrichs SC, Coffin VL, Koob GF (1995). Effects of the dopamine D-1 antagonist SCH 23390 microinjected into the accumbens, amygdala or striatum on cocaine self-administration in the rat. Brain Res 692: 147-156.

Callahan PM, Cunningham KA (1995). Modulation of the discriminative stimulus properties of cocaine by $5-\mathrm{HT} 1 \mathrm{~B}$ and 5-HT2C receptors. J Pharmacol Exp Ther 274: 1414-1424.

Capriles N, Rodaros D, Sorge RE, Stewart J (2003). A role for the prefrontal cortex in stress- and cocaine-induced reinstatement of cocaine seeking in rats. Psychopharmacology (Berl) 168: 66-74.

Carroll ME, France CP, Meisch RA (1981). Intravenous selfadministration of etonitazene, cocaine and phencyclidine in rats during food deprivation and satiation. J Pharmacol Exp Ther 217: 241-247.

Childress A, Ehrman R, McLellan AT, O’Brien C (1988). Conditioned craving and arousal in cocaine addiction: a preliminary report. NIDA Res Monogr 81: 74-80.

Ciccocioppo R, Sanna PP, Weiss F (2001). Cocaine-predictive stimulus induces drug-seeking behavior and neural activation in limbic brain regions after multiple months of abstinence: reversal by $\mathrm{D}(1)$ antagonists. Proc Natl Acad Sci USA 98: 1976-1981.

de Wit H, Stewart J (1981). Reinstatement of cocaine-reinforced responding in the rat. Psychopharmacology (Berl) 75: 134-143.

Deroche V, Le Moal M, Piazza PV (1999). Cocaine self-administration increases the incentive motivational properties of the drug in rats. Eur J Neurosci 11: 2731-2736.

Di Chiara G (1999). Drug addiction as a dopamine-dependent associative learning disorder. Eur J Pharmacol 375: 13-30.

Di Ciano P, Everitt BJ (2004a). Contribution of the ventral tegmental area to cocaine-seeking maintained by a drug-paired conditioned stimulus in rats. Eur J Neurosci 19: 1661-1667.

Di Ciano P, Everitt BJ (2004b). Direct interactions between the basolateral amygdala and nucleus accumbens core underlie cocaine-seeking behavior by rats. J Neurosci 24: 7167-7173.

Drouin C, Waterhouse BD (2004). Cocaine-induced $v s$. behaviourrelated alterations of spontaneous and evoked discharge of somatosensory cortical neurons. Eur J Neurosci 19: 1016-1026.

Duffy RA, Hunt MA, Wamsley JK, McQuade RD (2000). In vivo autoradiography of $[3 \mathrm{H}] \mathrm{SCH} 39166$ in rat brain: selective displacement by D1/D5 antagonists. J Chem Neuroanat 19: 41-46.

Epping-Jordan MP, Markou A, Koob GF (1998). The dopamine D-1 receptor antagonist SCH 23390 injected into the dorsolateral bed nucleus of the stria terminalis decreased cocaine reinforcement in the rat. Brain Res 784: 105-115.

Filip M, Bubar MJ, Cunningham KA (2004). Contribution of serotonin (5-hydroxytryptamine; 5-HT) 5-HT2 receptor subtypes to the hyperlocomotor effects of cocaine: acute and chronic pharmacological analyses. J Pharmacol Exp Ther 310: 1246-1254.

Fletcher PJ, Chintoh AF, Sinyard J, Higgins GA (2004). Injection of the 5-HT2C receptor agonist Ro60-0175 into the ventral tegmental area reduces cocaine-induced locomotor activity and cocaine self-administration. Neuropsychopharmacology 29: 308-318.

Fletcher PJ, Grottick AJ, Higgins GA (2002). Differential effects of the 5-HT(2A) receptor antagonist M100907 and the 5-HT(2C) receptor antagonist SB242084 on cocaine-induced locomotor activity, cocaine self-administration and cocaine-induced reinstatement of responding. Neuropsychopharmacology 27: 576-586.

Fuchs RA, See RE (2002). Basolateral amygdala inactivation abolishes conditioned stimulus- and heroin-induced reinstatement of extinguished heroin-seeking behavior in rats. Psychopharmacology (Berl) 160: 425-433.

Fuchs RA, Weber SM, Rice HJ, Neisewander JL (2002). Effects of excitotoxic lesions of the basolateral amygdala on cocaineseeking behavior and cocaine conditioned place preference in rats. Brain Res 929: 15-25.

Garavan H, Pankiewicz J, Bloom A, Cho JK, Sperry L, Ross TJ et al (2000). Cue-induced cocaine craving: neuroanatomical specificity for drug users and drug stimuli. Am J Psychiatry 157: 1789-1798.

Goeders NE, Smith JE (1993). Intracranial cocaine self-administration into the medial prefrontal cortex increases dopamine turnover in the nucleus accumbens. J Pharmacol Exp Ther 265: 592-600.

Grimm JW, Hope BT, Wise RA, Shaham Y (2001). Neuroadaptation. Incubation of cocaine craving after withdrawal. Nature 412: 141-142.

Grimm JW, See RE (2000). Dissociation of primary and secondary reward-relevant limbic nuclei in an animal model of relapse. Neuropsychopharmacology 22: 473-479.

Groenewegen HJ, Berendse HW, Wolters JG, Lohman AH (1990). The anatomical relationship of the prefrontal cortex with the striatopallidal system, the thalamus and the amygdala: evidence for a parallel organization. Prog Brain Res 85: 95-116; discussion 116-118.

Grottick AJ, Fletcher PJ, Higgins GA (2000). Studies to investigate the role of 5-HT(2C) receptors on cocaine- and food-maintained behavior. J Pharmacol Exp Ther 295: 1183-1191.

Hiroi N, White NM (1991). The amphetamine conditioned place preference: differential involvement of dopamine receptor subtypes and two dopaminergic terminal areas. Brain Res 552: 141-152.

Hunt GE, McGregor IS (1998). Rewarding brain stimulation induces only sparse Fos-like immunoreactivity in dopaminergic neurons. Neuroscience 83: 501-515.

Hurd YL, McGregor A, Ponten M (1997). In vivo dopamine levels modulate cocaine self-administration behavior in the rat: D1 dopamine receptor involvement. Eur J Neurosci 9: 2541-2548.

Kantak KM, Black Y, Valencia E, Green-Jordan K, Eichenbaum HB (2002). Dissociable effects of lidocaine inactivation of the rostral and caudal basolateral amygdala on the maintenance and reinstatement of cocaine-seeking behavior in rats. $J$ Neurosci 22: $1126-1136$.

Khroyan TV, Barrett-Larimore RL, Rowlett JK, Spealman RD (2000). Dopamine D1- and D2-like receptor mechanisms in relapse to cocaine-seeking behavior: effects of selective antagonists and agonists. J Pharmacol Exp Ther 294: 680-687.

Khroyan TV, Platt DM, Rowlett JK, Spealman RD (2003). Attenuation of relapse to cocaine seeking by dopamine D1 receptor agonists and antagonists in non-human primates. Psychopharmacology (Berl) 168: 124-131.

Kita H, Kitai ST (1990). Amygdaloid projections to the frontal cortex and striatum in the rat. J Comp Neurol 298: 40-49.

Kruzich PJ, See RE (2001). Differential contributions of the basolateral and central amygdala in the acquisition and expression of conditioned relapse to cocaine-seeking behavior. J Neurosci 21: RC155.

Kuzhikandathil EV, Oxford GS (2002). Classic D1 dopamine receptor antagonist $R$-(+)-7-chloro-8-hydroxy-3-methyl-1-phenyl2,3,4,5-tetrahydro-1H-3-benzaze pine hydrochloride (SCH23390) directly inhibits $\mathrm{G}$ protein-coupled inwardly rectifying potassium channels. Mol Pharmacol 62: 119-126. 
Lu L, Hope BT, Dempsey J, Liu SY, Bossert JM, Shaham Y (2005). Central amygdala ERK signaling pathway is critical to incubation of cocaine craving. Nat Neurosci 8: 212-219.

McDonald AJ (1991). Topographical organization of amygdaloid projections to the caudatoputamen, nucleus accumbens, and related striatal-like areas of the rat brain. Neuroscience 44: 15-33.

McFarland K, Kalivas PW (2001). The circuitry mediating cocaineinduced reinstatement of drug-seeking behavior. J Neurosci 21: 8655-8663.

McFarland K, Lapish CC, Kalivas PW (2003). Prefrontal glutamate release into the core of the nucleus accumbens mediates cocaineinduced reinstatement of drug-seeking behavior. J Neurosci 23: 3531-3537.

McGregor A, Roberts DCS (1993). Dopaminergic antagonism within the nucleus accumbens or amygdala produces differential effects on intravenous cocaine self-administration under fixed and progressive ratio schedules of reinforcement. Brain Res 624: 245-252.

McLaughlin J, See RE (2003). Selective inactivation of the dorsomedial prefrontal cortex and the basolateral amygdala attenuates conditioned-cued reinstatement of extinguished cocaine-seeking behavior in rats. Psychopharmacology (Berl) 168: $57-65$.

Meil WM, See RE (1997). Lesions of the basolateral amygdala abolish the ability of drug associated cues to reinstate responding during withdrawal from self-administered cocaine. Behav Brain Res 87: 139-148.

Millan MJ, Newman-Tancredi A, Quentric Y, Cussac D (2001). The 'selective' dopamine D1 receptor antagonist, $\mathrm{SCH} 23390$, is a potent and high efficacy agonist at cloned human serotonin2C receptors. Psychopharmacology (Berl) 156: 58-62.

Mowrer O, Jones H (1945). Habit strength as a function of the pattern of reinforcement. J Exp Psychiatry 35: 293-311.

Nader K, LeDoux JE (1999). Inhibition of the mesoamygdala dopaminergic pathway impairs the retrieval of conditioned fear associations. Behav Neurosci 113: 891-901.

National Research Council (1996). Guide for the Care and Use of Laboratory Animals. National Academy Press: Washington, DC.

Neisewander JL, Baker DA, Fuchs RA, Tran-Nguyen LT, Palmer A, Marshall JF (2000). Fos protein expression and cocaine-seeking behavior in rats after exposure to a cocaine self-administration environment. J Neurosci 20: 798-805.

Neisewander JL, Fuchs RA, O'Dell LE, Khroyan TV (1998). Effects of SCH-23390 on dopamine D1 receptor occupancy and locomotion produced by intraaccumbens cocaine infusion. Synapse 30: 194-204.

Neisewander JL, O’Dell LE, Redmond JC (1995). Localization of dopamine receptor subtypes by intra-accumbens antagonists that reverse cocaine-induced locomotion. Brain Res 671: 201-212.

O'Dell LE, Sussman AN, Meyer KL, Neisewander JL (1999). Behavioral effects of psychomotor stimulant infusions into amygdaloid nuclei. Neuropsychopharmacology 20: 591-602.

Park WK, Bari AA, Jey AR, Anderson SM, Spealman RD, Rowlett JK et al (2002). Cocaine administered into the medial prefrontal cortex reinstates cocaine-seeking behavior by increasing AMPA receptor-mediated glutamate transmission in the nucleus accumbens. J Neurosci 22: 2916-2925.

Paxinos G, Watson C (1997). The Rat Brain in Stereotaxic Coordinates 3rd edn. Academic Press: San Diego.

Quinlan MG, Sharf R, Lee DY, Wise RA, Ranaldi R (2004). Blockade of substantia nigra dopamine D1 receptors reduces intravenous cocaine reward in rats. Psychopharmacology (Berl) 175: 53-59.

Ranaldi R, Wise RA (2001). Blockade of D1 dopamine receptors in the ventral tegmental area decreases cocaine reward: possible role for dendritically released dopamine. J Neurosci 21: 5841-5846.
Robledo P, Robbins TW, Everitt BJ (1996). Effects of excitotoxic lesions of the central amygdaloid nucleus on the potentiation of reward-related stimuli by intra-accumbens amphetamine. Behav Neurosci 110: 981-990.

See RE, Kruzich PJ, Grimm JW (2001). Dopamine, but not glutamate, receptor blockade in the basolateral amygdala attenuates conditioned reward in a rat model of relapse to cocaine-seeking behavior. Psychopharmacology (Berl) 154: 301-310.

Self DW, Barnhart WJ, Lehman DA, Nestler EJ (1996). Opposite modulation of cocaine-seeking behavior by D1- and D2-like dopamine receptor agonists. Science 271: 1586-1589.

Self DW, Karanian DA, Spencer JJ (2000). Effects of the novel D1 dopamine receptor agonist ABT-431 on cocaine self-administration and reinstatement. Ann N Y Acad Sci 909: 133-144.

Shinonaga Y, Takada M, Mizuno N (1994). Topographic organization of collateral projections from the basolateral amygdaloid nucleus to both the prefrontal cortex and nucleus accumbens in the rat. Neuroscience 58: 389-397.

Shu SY (2003). Marginal division of the neostriatum: a subcortical memory center. J Biomed Sci 10: 14-29.

Shu SY, Bao XM, Ning Q, Wu YM, Wang J, Leonard BE (2003a). New component of the limbic system: marginal division of the neostriatum that links the limbic system to the basal nucleus of Meynert. J Neurosci Res 71: 751-757.

Shu SY, Bao XM, Wu YM, Wang J, Leonard B (2003b). Hippocampal long-term potentiation attenuated by lesions in the marginal division of neostriatum. Neurochem Res 28: 743-747.

Sun W, Rebec GV (2005). The role of prefrontal cortex D1-like and D2-like receptors in cocaine-seeking behavior in rats. Psychopharmacology (Berl) 177: 315-323.

Thomas KL, Arroyo M, Everitt BJ (2003). Induction of the learning and plasticity-associated gene Zif268 following exposure to a discrete cocaine-associated stimulus. Eur J Neurosci 17: 1964-1972.

Thomas KL, Everitt BJ (2001). Limbic-cortical-ventral striatal activation during retrieval of a discrete cocaine-associated stimulus: a cellular imaging study with gamma protein kinase C expression. J Neurosci 21: 2526-2535.

Tran-Nguyen LT, Fuchs RA, Coffey GP, Baker DA, O'Dell LE, Neisewander JL (1998). Time-dependent changes in cocaineseeking behavior and extracellular dopamine levels in the amygdala during cocaine withdrawal. Neuropsychopharmacology 19: 48-59.

Wallace BC (1989). Psychological and environmental determinants of relapse in crack cocaine smokers. J Subst Abuse Treat 6: 95-106.

Wang GJ, Volkow ND, Fowler JS, Cervany P, Hitzemann RJ, Pappas NR et al (1999). Regional brain metabolic activation during craving elicited by recall of previous drug experiences. Life Sci 64: 775-784.

Weiss F, Martin-Fardon R, Ciccocioppo R, Kerr TM, Smith DL, Ben-Shahar O (2001). Enduring resistance to extinction of cocaine-seeking behavior induced by drug-related cues. Neuropsychopharmacology 25: 361-372.

Weissenborn R, Deroche V, Koob GF, Weiss F (1996). Effects of dopamine agonists and antagonists on cocaine-induced operant responding for a cocaine-associated stimulus. Psychopharmacology (Berl) 126: 311-322.

Whitelaw RB, Markou A, Robbins TW, Everitt BJ (1996). Excitotoxic lesions of the basolateral amygdala impair the acquisition of cocaine-seeking behaviour under a secondorder schedule of reinforcement. Psychopharmacology (Berl) 127: 213-224.

Yun IA, Fields HL (2003). Basolateral amygdala lesions impair both cue- and cocaine-induced reinstatement in animals trained on a discriminative stimulus task. Neuroscience 121: 747-757. 